\title{
Duodenal Stricture due to Necrotizing Pancreatitis following Endoscopic Ultrasound-Guided Ethanol Ablation of a Pancreatic Cyst: A Case Report
}

\author{
Jung Won Chun, Sang Hyub Lee, Jin Ho Choi, Woo Hyun Paik, Ji Kon Ryu and Yong-Tae Kim \\ Department of Internal Medicine and Liver Research Institute, Seoul National University Hospital, Seoul National University College of \\ Medicine, Seoul, Korea
}

The frequency of incidental detection of pancreatic cystic lesions (PCLs) is increasing because of the frequent use of cross-sectional imaging. The appropriate treatment for PCLs is challenging, and endoscopic ultrasound-guided ablation for PCLs has been reported in several studies. Although the feasibility and efficacy of this therapeutic modality have been shown, the safety issues associated with the procedure are still a concern. We present a case of a 61-year-old man who underwent ultrasound-guided ethanol ablation for PCL and needed repeated endoscopic balloon dilatation for severe duodenal stricture caused by necrotizing pancreatitis after the cyst ablation therapy. Clin Endosc 2019;52:510-515

Key Words: Pancreatic cyst; Duodenal obstruction; Pancreatitis, acute necrotizing; Endosonography

\section{INTRODUCTION}

Pancreatic cystic lesions (PCLs) are currently more frequently diagnosed because of increased use of abdominal cross-sectional imaging. ${ }^{1}$ PCLs are a heterogeneous disease group including non-neoplastic cysts, such as pseudocysts, and neoplastic cysts, such as mucinous cystic neoplasms, intraductal papillary mucinous neoplasms (IPMNs), and serous cystic neoplasms.

Treatment strategy for PCLs includes surgery or observation with regular imaging follow-up based on malignant risk stratifications. Endoscopic ultrasound-guided ethanol ablation (EUS-EA) has been recently attempted for PCLs with lower

Received: October 24, 2018 Revised: January 10, 2019

Accepted: January 11, 2019

Correspondence: Sang Hyub Lee

Department of Internal Medicine and Liver Research Institute, Seoul National University Hospital, Seoul National University College of Medicine, 101 Daehak-ro, Jongno-gu, Seoul 03080, Korea

Tel: +82-2-2072-4892, Fax: +82-2-762-9662, E-mail: gidoctor@snuh.org ORCID: https://orcid.org/0000-0003-2174-9726

(c) This is an Open Access article distributed under the terms of the Creative Commons Attribution Non-Commercial License (http://creativecommons.org/ licenses/by-nc/3.0) which permits unrestricted non-commercial use, distribution and reproduction in any medium, provided the original work is properly cited. risk of malignancy in several institutions. ${ }^{2}$ Herein, we report a case of a branch duct-IPMN (BD-IPMN) in a 61-year-old man who suffered from necrotizing pancreatitis and severe duodenal strictures after EUS-EA.

\section{CASE REPORT}

A 61-year-old man receiving medical treatment for hypertension and diabetes mellitus for 10 years was referred to our clinic for an incidentally-detected PCL. Surgical resection was recommended at an outside institution for a $2.2-\mathrm{cm}$ cystic lesion, presumably considered to be a BD-IPMN located in the uncinate process of the pancreas based on abdominal computed tomography (CT) findings (Fig. 1A). EUS revealed a 2-cm unilocular cystic lesion communicating with the pancreatic duct, without a definite mural nodule, cystic wall thickening, or dilatation of the main pancreatic duct (Fig. 1B). We decided to observe the PCL with imaging follow-up annually due to lack of high-risk stigmata or worrisome features.

The size of the cyst had increased from $2 \mathrm{~cm}$ to $3.6 \mathrm{~cm}$ during 2 years of follow-up (Fig. 1C, D). A follow-up EUS was performed to evaluate additional risky features; however, 
no features of high risk stigmata or worrisome features other than cystic size and fast growing tendency were detected. We decided to terminate the follow-up and perform the EUSEA instead of surgery, because the patient's skeptical position about surgical resection in spite of our repeated and strong recommendation regarding the operability of lesion and adequacy of surgery.

The cystic lesion was punctured with a 22-gauge needle and $6 \mathrm{~mL}$ of cyst fluid was totally aspirated; then, the lavage with equivalent volume of $0.9 \%$ normal saline solution was performed. A total of $10 \mathrm{~mL}$ of cyst fluid was aspirated and ethanol lavage with $99 \%$ ethanol was performed twice. The cyst was confirmed as indeterminate cyst based on the results of cyst fluid analysis with carcinoembryonic antigen level of $56.5 \mathrm{ng} / \mathrm{mL}$, amylase level of $103,980 \mathrm{U} / \mathrm{L}$, and negative result of cytology for malignant cells. ${ }^{3}$ The patient complained of abdominal pain 6 hours after the procedure. Conservative management for acute interstitial pancreatitis (Fig. 2A) was applied for a week. A few days after the discharge, abdominal pain and dyspepsia occurred and additional conservative treatment was needed for necrotizing pancreatitis over 2 weeks (Fig. 2B).

After 6 weeks from the procedure, the patient was admitted again with aggravated abdominal pain and recurrent vomiting. Abdominal CT showed walled-off necrosis (WON) around the pancreatic head accompanying the gastric outlet obstruction (Fig. 2C, D). EUS-guided drainage of WON and endoscopic balloon dilatation (EBD) for duodenal stricture (through which the endoscope could not be passed) were performed to relieve the symptoms (Fig. 3A-D). During each EBD session, a guidewire was passed through the narrowed portion of the duodenum between the second and third portion, and the stricture site was dilated three times with $\mathrm{CRE}^{\mathrm{TM}}$ Wireguided Balloon Dilators (Boston Scientific, Natick, MA, USA) of $20 \mathrm{~mm}$ in diameter at 6 atmospheres for 3 minutes. Despite the first EBD attempt, patient's symptoms persisted and dietary progress was poor. Additionally, no significant improvement of the duodenal stricture occurred in 2 weeks according to the results of a follow-up abdominal CT. Gastrojejunostomy was recommended for severe duodenal stricture without response to medical and endoscopic treatment, but the patient strongly refused surgery. Additional multiple EBDs were alternatively planned to alleviate the duodenal stricture. After a total of five consecutive sessions of EBD at 1-week intervals, patient's obstructive symptoms were finally relieved (Fig. 3E-L) and he was discharged from the hospital after 5
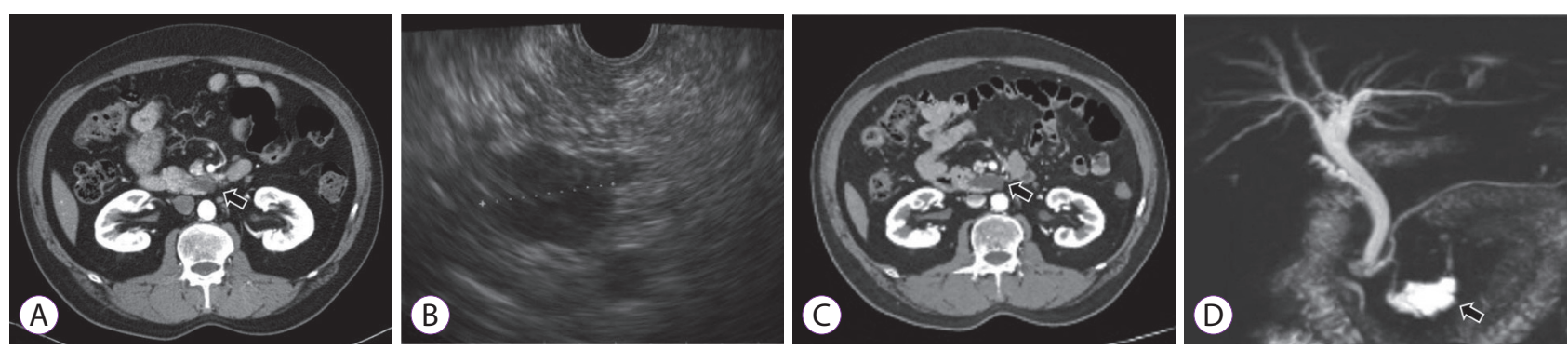

Fig. 1. Imaging evaluations of pancreatic cyst lesion. (A) Initial computed tomography (CT) scan revealed a 2.2-cm branch duct-intraductal papillary mucinous neoplasm in the uncinate process of the pancreas (arrow). (B) Initial endoscopic ultrasonography findings indicated a 2-cm unilocular cyst in the uncinate process without a definite mural nodule or pancreatic duct dilatation. (C) A follow-up CT showed a 3.5-cm cystic lesion with exophytic portion in the uncinate process, increased in size (arrow). (D) Magnetic resonance cholangiopancreatography revealed a 3.6-cm pleomorphic cystic lesion in the pancreas head with pancreatic duct communication and without main pancreatic duct dilatation or solid mural nodule (arrow).
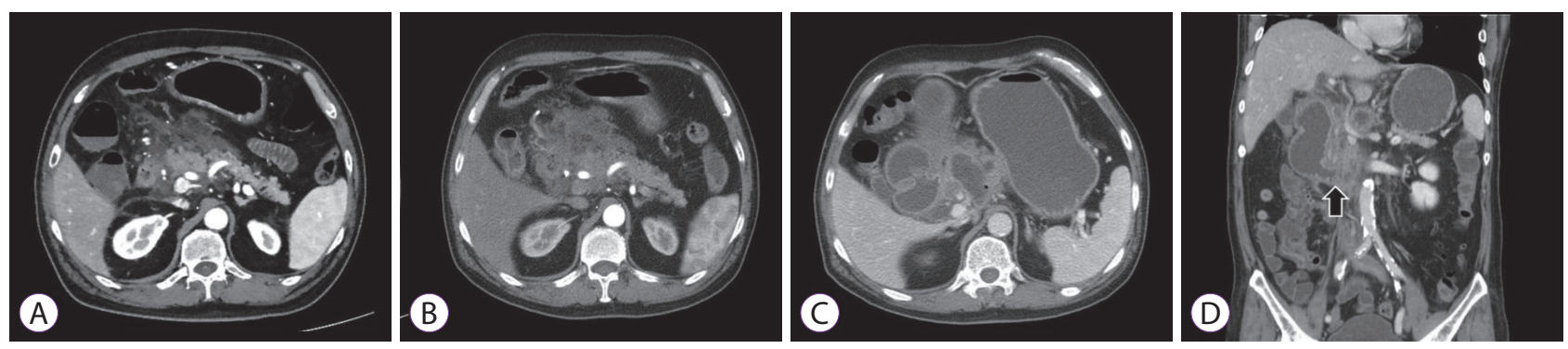

Fig. 2. Abdominal computed tomography (CT) findings. (A) Pancreatic swelling with extensive peripancreatic infiltration and fluid collection suggesting acute interstitial edematous pancreatitis. (B) Hypoenhancement of the pancreas with extensive areas of necrosis showing necrotizing pancreatitis. (C) A follow-up CT after 6 weeks revealed walled-off pancreatic necrosis. (D) Third duodenal portion narrowing (arrow) associated with upstream dilatation of the duodenum and stomach, suggesting gastric outlet obstruction. 
weeks of hospital stay following the confirmation of smooth diet proceeding. Currently, the patient is followed up in the outpatient department of our hospital without recurrence of symptoms for 11 months, and abdominal CT revealed complete remission of the cystic lesion (Fig. 4).

\section{DISCUSSION}

The treatment of PCLs is either surgical resection or conservative follow-up based on malignant transformation risk. According to the revised Fukuoka guideline for IPMN, surgical resection is recommended for BD-IPMNs with highrisk stigmata. ${ }^{4}$ Patients can be followed up according to the cyst size stratification in the absence of worrisome features. ${ }^{4}$ However, there is no clearly specified suggestion on how to deal with any changes during the surveillance, and patient management depends on the clinical judgment of physicians.
In the presented case, based on two newly appeared worrisome features, namely rapidly growing and the size over $3 \mathrm{~cm}$, we decided to perform EUS-EA for this PCL of the uncinate process because the patient completely refused any surgical therapeutic approach. Despite having obtained the result of complete remission of the PCL, necrotizing pancreatitis occurred and eventually resulted in WON accompanying a severe duodenal stricture, which put a great medical burden on the patient because of repeated endoscopic sessions and longterm hospitalization.

Although surgical resection is the definitive treatment for the PCLs with malignant potential, it is also associated with morbidity and occasional mortality. Additionally, it is more burdensome when pancreaticoduodenectomy is needed for a lesion located in the head or uncinate process of the pancreas. As the development of diagnostic techniques and the understanding of the natural course of PCLs are deepened, treatment strategies are more conservative with a highly selective
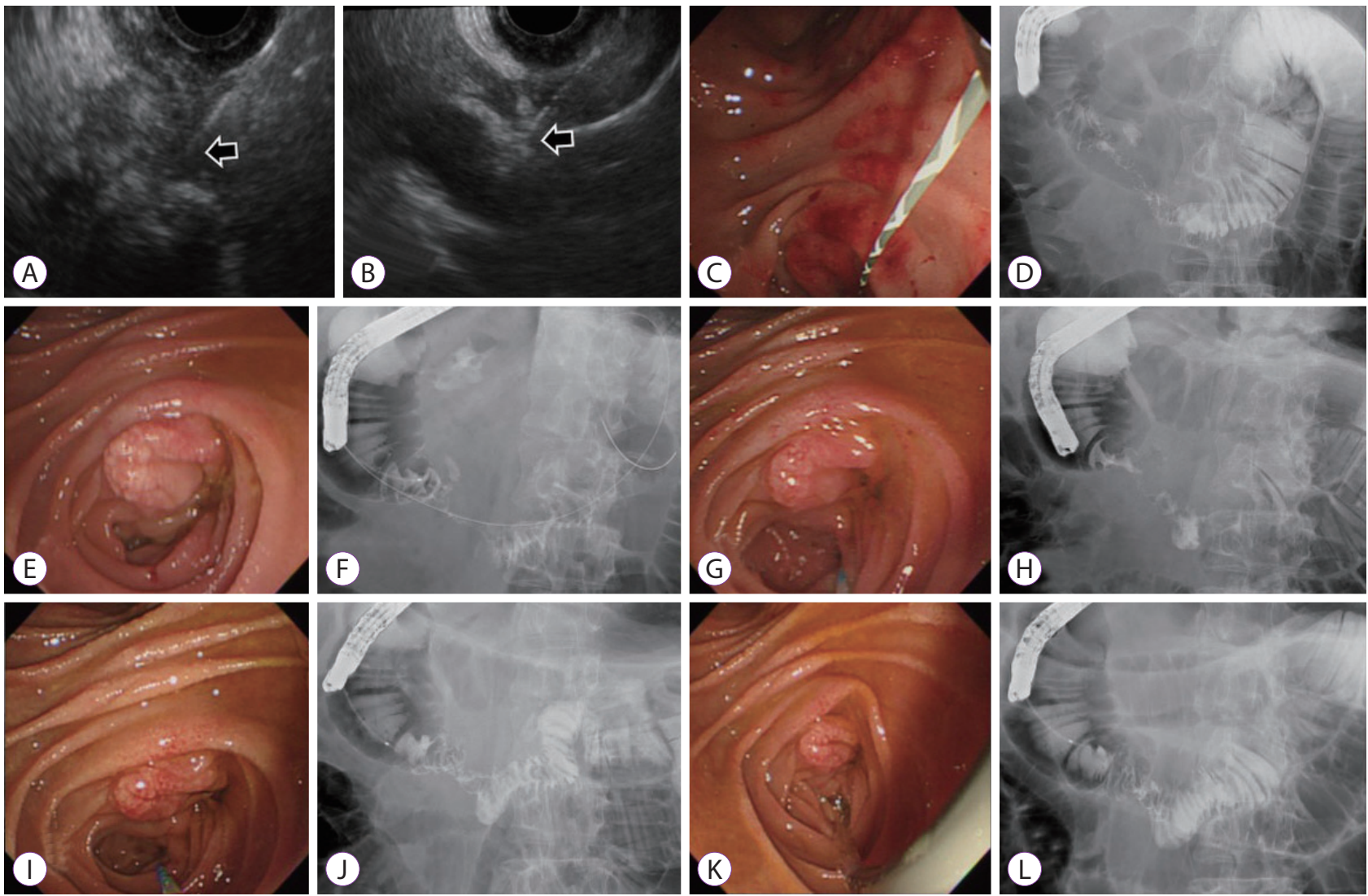

Fig. 3. Endoscopic balloon dilation (EBD) of the duodenal stricture. (A) Endoscopic ultrasonography (EUS) showing peripancreatic necrosis and aspiration attempts (arrow). (B) Part of walled-off necrosis was drained by EUS-guided aspiration using 19-gauge needle (arrow). (C) The stricture observed in the second part of the duodenum was not passed by the duodenoscope. The guidewire was passed to the third portion and EBD with the diameter of 20 mm was performed. (D) The fluoroscopy showing dye passed through the third portion of duodenum, but not adequate. (E) After one week from first EBD, luminal narrowing was found in the second and third portions of the duodenum. (F) The second EBD was attempted. (G) Duodenoscope passage was still difficult due to narrowed lumen after a week. (H) Dye passage was confirmed after third EBD. (I, J) The fourth EBD was performed 3 times for 3 minutes, and the stricture was alleviated. (K, L) The improved state of stricture was confirmed after the 5 th EBD. 
surgical approach. ${ }^{5}$ In this context, endoscopic treatment has been shown to be a possible complementary therapeutic modality after several studies reported the efficacy and feasibility with certain levels of complete resolution of cysts (9\%-85\%) (Table 1). ${ }^{3,6-17}$

EUS-EA is considered a relatively safe procedure, based on the results of several previous studies. ${ }^{3,6-9}$ The possible adverse events include abdominal pain, fever, and acute pancreatitis, and usually resolve spontaneously. Severe complications requiring continuous hospitalization occurred only in 8 cases, most of them were acute pancreatitis that is the major concern of the EUS-EA (Table 1 ). ${ }^{18}$ According to the results of a retrospective study performed at our center, most common complications of EUS-EA were mild abdominal pain and acute pancreatitis that occurred in $24 \%$ and $9 \%$ of patients, respectively. ${ }^{19}$ Of them, a severe adverse event occurred in only one patient described in the current case report.

In the development of acute pancreatitis, spillage of ethanol to pancreatic parenchyma is thought to result in focal inflammation. ${ }^{7}$ Therefore, a precise and experienced handling of the fine needle within the cyst is essential for avoiding acute pancreatitis, and cyst lesions greater than $2 \mathrm{~cm}$ in diameter are preferred to be addressed by EUS-EA. The communication with the main pancreatic duct that was present in this case is another factor affecting the development of procedure-related pancreatitis. ${ }^{8,10}$ Furthermore, needling through a different angle may increase the risk of adverse events. ${ }^{20}$ Multiple logistic regression analysis using our hospital data showed that a clinical diagnosis of IPMN (odds ratio [OR], 4.232; 95\% confidence interval [CI], 1.349-13.282), PCLs of the uncinate process (OR, 2.849; 95\% CI, 1.031-7.873), multilocular cyst (OR, 4.596; 95\%
CI, 1.375-15.372), and exophytic portion (OR, 3.158; 95\% CI, 1.739-5.736) can also increase risk of abdominal pain and pancreatitis after EUS-EA. ${ }^{19}$

In this regard, the PCL in the present case was associated with a high risk of pancreatitis after EUA-EA. In addition, two repeated punctures were performed during the procedure due to the poor patient cooperation. Repeated puncture might induce ethanol leakage and eventually result in peripancreatic fat necrosis and inflammation leading to severe duodenal obstruction.

In the management of complications, conservative treatment with nasojejunal tube feeding for sufficient time would be a possible option for similar cases in the future, because the relief of duodenal obstruction seems to have relied on a lot of the improvement of inflammation over time with remission of the necrotizing pancreatitis itself.

Although no definite indications for EUS-EA for PCLs are currently available, we performed the procedure based on the following tentative indications: unilocular or oligolocular cysts larger than $2 \mathrm{~cm}$ as cysts that increases in size during the follow-up. ${ }^{3,15}$ IPMN does not seem to be a good candidate for EUS-EA because it is prone to adverse events and complete remission rate is expected to be poor. Decision of EUSEA as the second best therapeutic option for PCLs requires cautious consideration about the risk factors mentioned above and stricter selection criteria with PCLs at high risk of procedure-related adverse events. ${ }^{9,11,14,16}$ Recently, alcohol-free ablation has been introduced in order to reduce the post-procedural adverse events, ${ }^{16}$ but the use of chemotherapeutic agent for cystic ablation is not allowed for patients in Korea other than for research purposes.
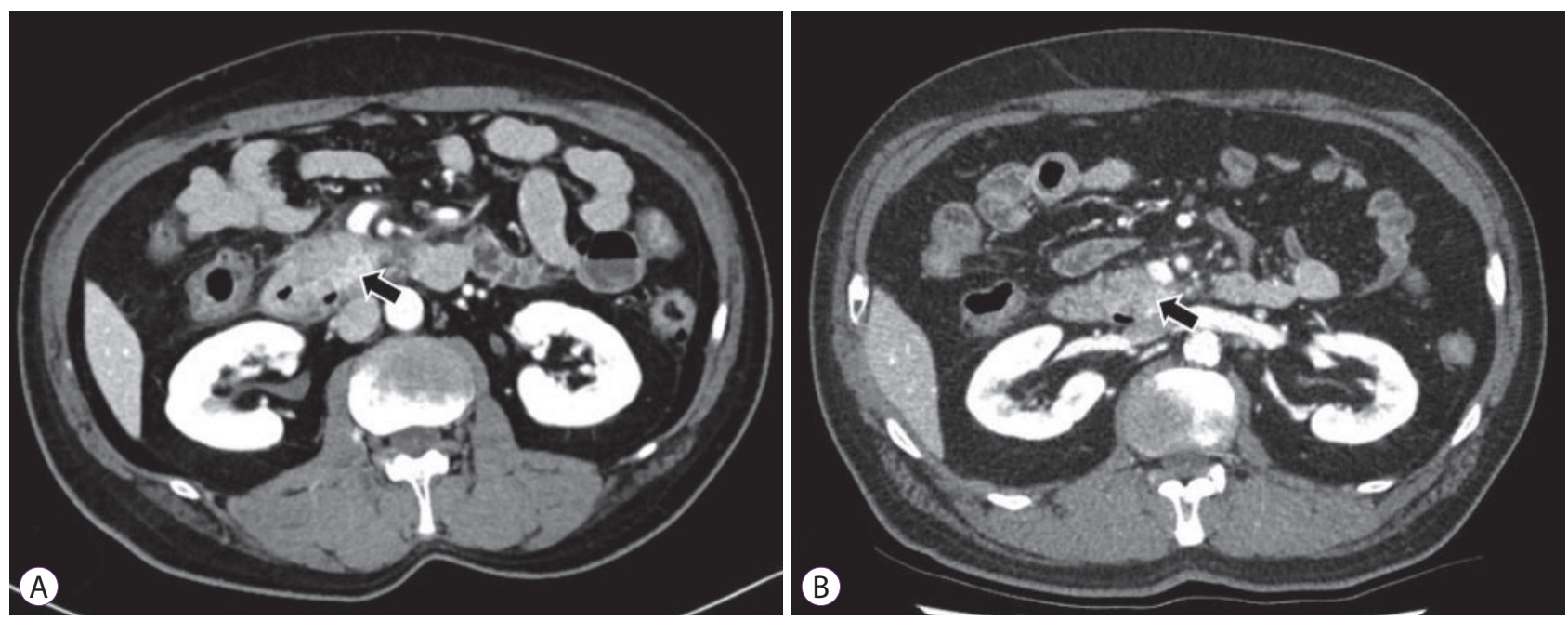

Fig. 4. Computed tomography (CT) images after resolution of procedure-related adverse events. (A) Abdominal CT scan performed 1 month after the last discharge, showed interval regression of pancreatitis and no duodenal obstruction (arrow). (B) Complete remission of pancreatic cystic lesion was revealed by the follow-up CT scan performed 9 months after cyst ablation (arrow). 
Table 1. Review of Previous Studies for Endoscopic Ultrasound-Guided Ablation in Pancreatic Cystic Lesions

\begin{tabular}{|c|c|c|c|c|c|c|c|c|}
\hline Study & $n$ & Agents & Diagnosis $(n / \%)$ & Size $(\mathbf{m m})$ & $\begin{array}{l}\text { Follow-up } \\
\quad(\mathrm{mo})\end{array}$ & $\operatorname{CR}(n / \%)$ & Total AE (n) & $\begin{array}{l}\text { Severe AE } \\
\quad(n)\end{array}$ \\
\hline Gan et al. $^{6}$ & 23 & $\mathrm{E}$ & $\begin{array}{l}\text { MCN 14/61 } \\
\text { IPMN 3/13 } \\
\text { SCN 3/13 } \\
\text { PC } 1 / 4 \\
\text { Unknown 2/8 }\end{array}$ & $\begin{array}{c}19.4 \\
(6-37)\end{array}$ & $6-12$ & $8 / 35$ & (0) & (0) \\
\hline Oh et $\mathrm{al}^{7}$ & 14 & $E+P$ & $\begin{array}{l}\text { MCN 2/14 } \\
\text { SCN 3/21 } \\
\text { Lymphangioma 3/21 } \\
\text { Unknown 6/43 }\end{array}$ & 25.5 & $\begin{array}{c}9 \\
(6-23)\end{array}$ & $11 / 79$ & $\begin{array}{l}\text { Abdominal pain (1) } \\
\text { AP (1) }\end{array}$ & (0) \\
\hline Oh et $\mathrm{al}^{8}$ & 10 & $E+P$ & $\begin{array}{l}\text { MCN 3/30 } \\
\text { SCN 4/40 } \\
\text { Unknown 3/30 }\end{array}$ & $\begin{array}{c}29.5 \\
(20-68)\end{array}$ & $\begin{array}{c}8.5 \\
(6-18)\end{array}$ & $6 / 60$ & $\mathrm{AP}(1 / 10)$ & (0) \\
\hline DeWitt et al. ${ }^{9}$ & $\begin{array}{l}25 \\
17\end{array}$ & $\begin{array}{c}\mathrm{E} \\
\text { Saline }\end{array}$ & $\begin{array}{l}\text { MCN 17/40 } \\
\text { IPMN } 17 / 40 \\
\text { SCN 5/12 } \\
\text { PC } 3 / 7\end{array}$ & $\begin{array}{c}20.5 \\
(10-40)\end{array}$ & $3-4$ & $12 / 33$ & $\begin{array}{l}\text { Abdominal pain (7) } \\
\text { AP (1) } \\
\text { Cystic hemorrhage (1) }\end{array}$ & $\mathrm{AP}(1)$ \\
\hline Oh et al. ${ }^{10}$ & 52 & $\mathrm{E}+\mathrm{P}$ & $\begin{array}{l}\text { MCN 9/17 } \\
\text { SCN } 15 / 29 \\
\text { PC } 2 / 4 \\
\text { Unknown 26/50 }\end{array}$ & $\begin{array}{c}31.8 \\
(17-68)\end{array}$ & $\begin{array}{c}21.7 \\
(2-44)\end{array}$ & $29 / 62$ & $\begin{array}{l}\text { Fever (1) } \\
\text { Abdominal pain (1) } \\
\text { AP (1) } \\
\text { Splenic vein obliteration }(1)\end{array}$ & (0) \\
\hline DiMaio et al. ${ }^{11}$ & 13 & $\mathrm{E}$ & IPMN 13/100 & 20.1 & 13.4 & $5 / 38$ & Abdominal pain (1) & $(0)$ \\
\hline Caillol et al. ${ }^{12}$ & 13 & $\mathrm{E}$ & MCN 13/100 & $\begin{array}{c}24 \\
(11-50)\end{array}$ & $\begin{array}{c}26 \\
(4-118)\end{array}$ & $11 / 85$ & (0) & (0) \\
\hline DeWitt et al. ${ }^{13}$ & 21 & $E+P$ & $\begin{array}{l}\text { MCN 12/55 } \\
\text { IPMN 6/27 } \\
\text { SCN 4/18 }\end{array}$ & $\begin{array}{c}25 \\
(15-43)\end{array}$ & $\begin{array}{c}27 \\
(17-42)\end{array}$ & $10 / 50$ & $\begin{array}{l}\text { Abdominal pain (4) } \\
\text { AP (3) } \\
\text { Peritonitis (1) } \\
\text { Gastric wall cyst (1) }\end{array}$ & $\begin{array}{c}\mathrm{AP}(3) \\
\text { Peritonitis } \\
\quad(1)\end{array}$ \\
\hline Park et al. ${ }^{3}$ & 91 & $\mathrm{E}$ & $\begin{array}{l}\text { MCN 12/13 } \\
\text { IPMN 9/10 } \\
\text { SCN 33/36 } \\
\text { Unknown 28/31 }\end{array}$ & $\begin{array}{c}30 \\
(20-50)\end{array}$ & $\begin{array}{c}40 \\
(13-117)\end{array}$ & $41 / 45$ & $\begin{array}{l}\text { Fever (8) } \\
\text { Abdominal pain (18) } \\
\text { AP (3) }\end{array}$ & (0) \\
\hline Gómez et al. $^{14}$ & 23 & $\mathrm{E}$ & $\begin{array}{l}\text { MCN 4/17.5 } \\
\text { IPMN 15/65 } \\
\text { Unknown 4/17.5 }\end{array}$ & $\begin{array}{c}27.5 \\
(15-50)\end{array}$ & $\begin{array}{c}46 \\
(15-91)\end{array}$ & $2 / 9$ & $\begin{array}{l}\text { Abdominal pain (1) } \\
\text { AP (1) }\end{array}$ & $\mathrm{AP}(1)$ \\
\hline Choi et al. ${ }^{15}$ & 158 & $E+P$ & $\begin{array}{l}\text { MCN 71/43 } \\
\text { IPMN 11/7 } \\
\text { SCN 16/10 } \\
\text { Unknown 63/40 }\end{array}$ & $\begin{array}{c}32 \\
(26-41)\end{array}$ & $\begin{array}{c}72 \\
(50-85)\end{array}$ & $114 / 72$ & $\begin{array}{l}\text { Fever (1) } \\
\text { Pericystic spillage (1) } \\
\text { Cystic hemorrhage (1) } \\
\text { AP (6) } \\
\text { Pseudocyst (2) } \\
\text { Abscess formation (2) } \\
\text { PVT (1) } \\
\text { Splenic vein obliteration (1) } \\
\text { MPD stricture (1) }\end{array}$ & PVT (1) \\
\hline Moyer et al. ${ }^{16}$ & $\begin{array}{l}18 \\
21\end{array}$ & $\begin{array}{c}E+G+P \\
G+P\end{array}$ & $\begin{array}{l}\text { MCN 9/23 } \\
\text { IPMN 27/69 } \\
\text { Unknown 3/8 }\end{array}$ & $\begin{array}{c}25 \\
(15.5-42)\end{array}$ & 12 & $\begin{array}{l}11 / 61 \\
14 / 67\end{array}$ & $\begin{array}{l}\text { Abdominal pain (4) } \\
\text { AP (1) }\end{array}$ & $\mathrm{AP}(1)$ \\
\hline Choi et al. ${ }^{17}$ & 118 & $\mathrm{E}$ & $\begin{array}{l}\text { MCN } 14 / 12 \\
\text { SCN } 40 / 34 \\
\text { IPMN } 10 / 8 \\
\text { PC } 15 / 13 \\
\text { Unknown } 39 / 33 \\
\end{array}$ & 23.13 & 78.8 & $27 / 32$ & N/A & (0) \\
\hline
\end{tabular}

$\mathrm{AE}$, adverse events; AP, acute pancreatitis; CR, complete remission; E, ethanol; G, gemcitabine; IPMN, intraductal papillary mucinous neoplasm; MCN, mucinous cystic neoplasm; MPD, main pancreatic duct; N/A, not applicable; P, paclitaxel; PC, pseudocyst; PVT, portal vein thrombosis; SCN, serous cystic neoplasm. 
Although the incidence of severe complications related to EUS-EA is very low, our experience has raised awareness about the safety of EUS-EA. These complications can not only affect the patient's disability, but also reduce the quality of life and increase the medical expenditure. Therefore, EUS-EA should be prudently performed for the selected patients meeting strict inclusion criteria, with the expectation that severe complications, similar to those in the present case, can occur. Further studies are required to elucidate the indications of EUS-guided cyst ablation treatment to maximize the efficiency and minimize the procedure-related complications and to predict the risk factors for severe complications of EUS-guided ablation.

\section{Conflicts of Interest}

The authors have no financial conflicts of interest.

\section{Author Contributions}

Conceptualization: Sang Hyub Lee

Supervision: SHL, Yong-Tae Kim

Writing-original draft: Jung Won Chun

Writing-review\&editing: JWC, SHL, Jin Ho Choi, Woo Hyun Paik, Ji Kon Ryu

\section{REFERENCES}

1. Basar O, Brugge WR. My treatment approach: pancreatic cysts. Mayo Clin Proc 2017;92:1519-1531.

2. Lee SH. [Endoscopic treatment for pancreatic cystic lesions]. Korean J Gastroenterol 2018;71:10-17.

3. Park JK, Song BJ, Ryu JK, et al. Clinical outcomes of endoscopic ultrasonography-guided pancreatic cyst ablation. Pancreas 2016;45:889-894.

4. Tanaka M, Fernández-Del Castillo C, Kamisawa T, et al. Revisions of international consensus Fukuoka guidelines for the management of IPMN of the pancreas. Pancreatology 2017;17:738-753.

5. Allen PJ. The diagnosis and management of cystic lesions of the pancreas. Chin Clin Oncol 2017;6:60.

6. Gan SI, Thompson CC, Lauwers GY, Bounds BC, Brugge WR. Ethanol lavage of pancreatic cystic lesions: initial pilot study. Gastrointest En- dosc 2005;61:746-752.

7. Oh HC, Seo DW, Lee TY, et al. New treatment for cystic tumors of the pancreas: EUS-guided ethanol lavage with paclitaxel injection. Gastrointest Endosc 2008;67:636-642.

8. Oh HC, Seo DW, Kim SC, et al. Septated cystic tumors of the pancreas: is it possible to treat them by endoscopic ultrasonography-guided intervention? Scand J Gastroenterol 2009;44:242-247.

9. DeWitt J, McGreevy K, Schmidt CM, Brugge WR. EUS-guided ethanol versus saline solution lavage for pancreatic cysts: a randomized, double-blind study. Gastrointest Endosc 2009;70:710-723.

10. Oh HC, Seo DW, Song TJ, et al. Endoscopic ultrasonography-guided ethanol lavage with paclitaxel injection treats patients with pancreatic cysts. Gastroenterology 2011;140:172-179.

11. DiMaio CJ, DeWitt JM, Brugge WR. Ablation of pancreatic cystic lesions: the use of multiple endoscopic ultrasound-guided ethanol lavage sessions. Pancreas 2011;40:664-668.

12. Caillol F, Poincloux L, Bories E, et al. Ethanol lavage of 14 mucinous cysts of the pancreas: a retrospective study in two tertiary centers. Endosc Ultrasound 2012;1:48-52.

13. DeWitt JM, Al-Haddad M, Sherman S, et al. Alterations in cyst fluid genetics following endoscopic ultrasound-guided pancreatic cyst ablation with ethanol and paclitaxel. Endoscopy 2014;46:457-464.

14. Gómez V, Takahashi N, Levy MJ, et al. EUS-guided ethanol lavage does not reliably ablate pancreatic cystic neoplasms (with video). Gastrointest Endosc 2016;83:914-920.

15. Choi JH, Seo DW, Song TJ, et al. Long-term outcomes after endoscopic ultrasound-guided ablation of pancreatic cysts. Endoscopy 2017;49:866873.

16. Moyer MT, Sharzehi S, Mathew A, et al. The safety and efficacy of an alcohol-free pancreatic cyst ablation protocol. Gastroenterology 2017;153:1295-1303.

17. Choi JH, Lee SH, Choi YH, et al. Clinical outcomes of endoscopic ultrasound-guided ethanol ablation for pancreatic cystic lesions compared with the natural course: a propensity score matching analysis. Therap Adv Gastroenterol 2018;11:1756284818759929.

18. Cotton PB, Eisen GM, Aabakken L, et al. A lexicon for endoscopic adverse events: report of an ASGE workshop. Gastrointest Endosc 2010;71:446-454.

19. Choi JH, Lee SH, You MS, et al. Safety and adverse events of EUS-guided ethanol ablation for pancreatic cystic lesions: a single center experience. In: Joint Meeting of the Asian-Oceanic Pancreatic Association, the Korean Pancreatobiliary Association, and the Korean Pancreas Surgery Club 2018; 2018 Apr 26-28; Seoul, Korea. Seoul: Korean Pancreatobiliary Association, Korean Pancreas Surgery Club; 2018. p. 386-387.

20. Oh HC, Brugge WR. EUS-guided pancreatic cyst ablation: a critical review (with video). Gastrointest Endosc 2013;77:526-533. 